\title{
BMJ Open Rural-urban differentials in 30-day and 1-year mortality following first-ever heart failure hospitalisation in Western Australia: a population-based study using data linkage
}

Tiew-Hwa Katherine Teng, ${ }^{1}$ Judith M Katzenellenbogen, ${ }^{1}$ Joseph Hung, ${ }^{2}$ Matthew Knuiman, ${ }^{3}$ Frank M Sanfilippo, ${ }^{3}$ Elizabeth Geelhoed, ${ }^{3}$ Michael Hobbs, ${ }^{3}$ Sandra C Thompson ${ }^{1}$

To cite: Teng T-HK, Katzenellenbogen JM, Hung J, et al. Rural-urban differentials in 30-day and 1year mortality following firstever heart failure hospitalisation in Western Australia: a population-based study using data linkage. BMJ Open 2014;4:e004724. doi:10.1136/bmjopen-2013004724

- Prepublication history for this paper is available online. To view these files please visit the journal online (http://dx.doi.org/10.1136/ bmjopen-2013-004724).

Received 19 December 2013 Revised 31 March 2014 Accepted 10 April 2014

CrossMark

For numbered affiliations see end of article.

Correspondence to Dr Tiew-Hwa Katherine Teng; katherine.teng@uwa.edu.au

\section{ABSTRACT}

Objectives: We examined differentials in short-term (30-day mortality) and 1-year mortality (in 30-day survivors) following index (first-ever) hospitalisation for heart failure (HF), between rural and metropolitan patients resident in Western Australia.

Design: A population-based cohort study.

Setting: Hospitalised patients in Western Australia, Australia.

Participants: Index patients aged 20-84 years with a first-ever hospitalisation for HF between 2000 and 2009 (with no prior admissions for HF in previous 10 years), identified using the Western Australia linked health data.

Main outcome measures: 30-day and 1-year allcause mortality (in 30-day survivors) following index admission for HF.

Results: Of 17379 index patients with HF identified, $25.9 \%$ (4499) were from rural areas. Rural patients were significantly younger at first HF hospitalisation than metropolitan patients. Aboriginal patients comprised $1.9 \%$ of metropolitan and $17.2 \%$ of rural patients. Despite some statistical differences, the prevalence of antecedents including ischaemic heart disease, hypertension, diabetes and chronic kidney disease was high $(>20 \%)$ in both subpopulations. After adjusting for age only, patients from rural areas had a higher risk of 30-day death (OR $1.16(95 \% \mathrm{Cl} 1.01$ to 1.33)) and 1-year death in 30-day survivors (HR 1.11 $(95 \% \mathrm{Cl} 1.01$ to 1.23$))$. These relative risk estimates increased and remained significant after further progressive adjustments for Aboriginality, socioeconomic status, insurance status, emergency presentation, individual comorbidities and revascularisation with $\mathrm{OR} 1.25$ (1.06 to 1.48) for 30-day mortality and HR 1.13 (1.02 to 1.27) for 1-year mortality. The addition of the weighted Charlson index to the 30-day model improved the 'c' statistic (under the receiver operating characteristic curve) from 0.656 (using a variation of administrative claims model) to 0.714 .

\section{Strengths and limitations of this study}

- The strengths of this study lie in the quality and near complete ascertainment of the short-term and long-term mortality after first heart failure (HF) hospitalisation using the Western Australia linked administrative data.

- A principal diagnosis of HF in the Western Australia linked hospital morbidity data had been previously validated against the Boston diagnostic criteria with a positive predictive value of 92.4\% for 'definite' HF.

- We found a higher risk-adjusted 30-day and 1 -year mortality (in 30-day survivors) in rural (compared with metropolitan) patients following first HF hospitalisation in Western Australia between 2000 and 2009. The mortality disparity between rural and metropolitan patients persisted after adjustment for Aboriginality, other major sociodemographic differences and comorbidities.

- However, we do not have information to adjust for medications in our cohort and sociodeprivation was derived using an area-based measure which could give rise to potential misclassification.

- The findings have implications for enhancing chronic disease management and secondary prevention of $\mathrm{HF}$ in rural Western Australia.

Conclusions: Remoteness and variable access to healthcare can cause important disparities in health outcomes. Rural patients with HF in Western Australia have poorer risk-adjusted outcomes compared with metropolitan patients. This finding has important implications for chronic disease management and provision of health services in rural Australia.

\section{INTRODUCTION}

The management of chronic diseases is an increasing public health concern in rural 
areas. ${ }^{1}$ Australians living in regional and remote areas generally have poorer health than metropolitan residents, ${ }^{1}$ with higher rates of chronic diseases reported in these areas. ${ }^{2}$ The health needs of many regional and remote communities have not been met, ${ }^{3}$ despite many initiatives to address geographical inequalities over the last decade. Generally, rural populations experience poorer access to and limited availability of health and allied healthcare services with the provision of healthcare services inversely proportional to the distance from capital cities. ${ }^{1}$

Rural inhabitants have a constellation of risk factors and experience greater socioeconomic disadvantage ${ }^{4}$ which also affect people's need for and access to health services. ${ }^{2}$ Any understanding of the rural dimension in health needs to be inclusive of Indigenous Australians as Aboriginal and Torres Strait Islander peoples are more likely to live in non-metropolitan areas. ${ }^{5}$ Additionally, cardiovascular disease (CVD), including heart failure $(\mathrm{HF})$, is a major cause of premature death in the indigenous population in Australia. ${ }^{6}$

HF is a chronic debilitating disease, with $50-60 \%$ mortality within 5 years. ${ }^{7} \mathrm{HF}$ is a major cause of death from CVD and outcomes can be adversely affected by restricted access to hospital and continuing care as well as the standard of clinical management. ${ }^{8}$ Therefore death rates from $\mathrm{HF}$ are a useful indicator of disparities in health access and care between rural and metropolitan patients. Previous studies from Canada ${ }^{9}{ }^{10}$ suggest important disparities in the outcomes of HF among metropolitan versus rural populations. Although Canada has similarities in the universal healthcare system and geography as Australia, there are no previous studies (on HF) in the Australian context.

We examined differentials in 30-day mortality and 1-year mortality (in 30-day survivors) following index (first-ever) hospitalisation for $\mathrm{HF}$, between rural and metropolitan patients resident in Western Australia .

\section{METHODOLOGY}

\section{Study setting and data sources}

The study was performed in Western Australia, which is geographically the largest of six states in Australia, with a land mass spanning 2.53 million $\mathrm{km}^{2}$. Based on the 2006 census, about $27 \%$ of the 2.5 million inhabitants in Western Australia lived in what is referred as regional and remote Australia. Western Australia is also home to the third largest number of Aboriginal Australians (13.2\% of total Aboriginal population). Australia has a universal healthcare system with free public acute hospital services, while allowing choice through a mix of public and private healthcare service providers.

Data were obtained from the Western Australian Data Linkage System, a population-based electronic linked health database which has been used extensively for health-related research. ${ }^{11}$ The Hospital Morbidity Data Collection (HMDC), a core dataset of the data linkage system, records information on hospital admissions throughout Western Australia, and is regularly audited for quality and accuracy. HMDC data are routinely linked to the Mortality register using probabilistic matching with greater than $99 \%$ accuracy. ${ }^{11}$

The Emergency Department Data Collection (EDDC) containing data on emergency department (ED) activity in Western Australia's public and private hospitals (under contract with the Western Australian government) was used to examine re-presentations to ED within 1 year of follow-up from index admission of HF.

Ours was a population-based cohort study using linked health data comprising all Western Australian residents aged 20-84 years who were admitted with a first hospitalisation for HF between 2000 and 2009 (with no previous admissions in the past 10 years), as described previously. ${ }^{12}{ }^{13}$ Inclusion in the study was based on a principal discharge diagnosis of HF or a secondary discharge diagnosis of $\mathrm{HF}$ with a principal discharge diagnosis of a cardiovascular condition, excluding acute myocardial infarction (AMI). The coding for $\mathrm{HF}$ as a principal discharge diagnosis in the HMDC has been previously validated against the Boston diagnostic criteria with a positive predictive value of $92.4 \%$ for 'definite' $\mathrm{HF}^{14}$

\section{Geographical classification}

Using residential postcodes, the Accessibility/ Remoteness Index of Australia (ARIA) classification was used to define the five categories of residence based on road distance to service centres: major cities, inner regional, outer regional, remote and very remote. ${ }^{15}$ For the regression analysis, place of residence was dichotomised into metropolitan residence (based on the greater Perth metropolitan city definition, ${ }^{16}$ including urban and some of inner regional) and rural residence (remainder of inner regional, outer regional, remote and very remote). A sensitivity analysis was performed using three geographical locations: (1) metropolitan, ${ }^{16}$ (2) regional (remainder of inner regional and all of outer regional) and (3) remote/very remote.

Socioeconomic Indices for Areas (SEIFA) ${ }^{17}$ were assigned to each patient based on residential postcodes and divided into quintiles, based on predefined cut-off points. The first quintile $(\mathrm{Q} 1)$ represents the most disadvantaged group and fifth quintile (Q5) the least.

\section{Comorbidities, interventions and procedures}

Individual comorbidities within 5 years or concurrent with index HF hospitalisation were identified: hypertension, atrial fibrillation, rheumatic fever and rheumatic heart disease, diabetes, valvular heart disease, chronic kidney disease, renal failure, chronic obstructive pulmonary disease (COPD), unstable angina, AMI, other ischaemic heart disease (IHD) and cerebrovascular disease. A Charlson comorbidity score ${ }^{18}$ was calculated for each index case by applying a fixed 5-year look-back period using the HMDC. We used the Dartmouth-Manitoba International Classification of 
Diseases (ICD) code assignments ${ }^{19}$ in calculating the Charlson score based on the original 17 Charlson comorbidities. Percutaneous coronary intervention or coronary artery bypass grafting and coronary angiography were similarly identified.

\section{Statistical analysis}

Descriptive analyses were used to characterise differences in the sociodemographics, comorbidities and interventions/procedures received between patients with HF who reside in metropolitan compared with rural areas. Means and SDs were calculated for continuous variables while frequencies and proportions were derived for categorical data. The Pearson $\chi^{2}$ test was used to test for differences in categorical variables and the $\mathrm{t}$ test or Mann-Whitney test for continuous variables. Multivariable logistic regression was used to determine predictors of death within 30 days, with ORs and their 95\% CIs reported. Multivariable Cox regression was used to determine survival to 1 year in 30-day survivors and HRs and their 95\% CIs reported. All patients admitted between 1 January 2000 and 30 November 2009 were included for 30-day survival analysis. For survival analysis to 1 year (from index admission), only patients admitted with their first HF between 2000 and 2008 were included.

Adjustment for cluster correlation with postcode as the cluster was examined and found to have a nonsignificant effect and hence not included in the final models.

\section{RESULTS}

Table 1 shows the geographic and sociodemographic characteristics of patients with first HF hospitalisation living in metropolitan $(\mathrm{n}=12 \mathrm{880}, 74.1 \%)$ and rural areas $(\mathrm{n}=4499,25.9 \%)$ between 2000 and 2009. A total of $33.6 \%$ of rural patients were from remote or very remote areas and the remainder from regional areas. Rural compared with metropolitan patients were significantly younger at first HF hospitalisation (mean age: 68 \pm 13 vs $71 \pm 12$ years, $\mathrm{p}<0.001$ ), and more likely men (59.3 vs $57.2 \%, \mathrm{p}=0.017$ ). Aboriginal (including Torres Strait Islander) patients comprised $17.2 \%$ of rural cases versus $1.9 \%$ of metropolitan cases. About $75 \%$ of rural patients with $\mathrm{HF}$ were seen at public regional or small district hospitals compared with less than $1 \%$ of metropolitan patients. Rural patients were less likely to have private health insurance compared with metropolitan patients (20.3\% vs $32.6 \%, \mathrm{p}<0.001)$. More than $50 \%$ of rural patients (vs $13.4 \%$ metropolitan patients) were in the two lowest quintiles (index of most disadvantages) of SEIFA, a proxy for socioeconomic status.

Profile of care prior to the index hospitalisation for $\mathrm{HF}$ and prehospital emergency medical service (EMS) coverage by ambulance was different in both subpopulations (table 1). Metropolitan (vs rural) patients were more likely to be managed by specialist clinicians
(25.2\% vs $15.1 \%$ rural); by contrast, more rural patients were cared for by general practitioners ( $18.4 \%$ vs $4.9 \%$ metropolitan). Metropolitan (vs rural) patients were more likely to be transported by EMS ambulance to admitting hospitals (38.5\% vs $19.4 \%$ ). About $65 \%$ of rural patients depended on private/public transport to get to admitting hospitals. Notably, rural (vs metropolitan) patients were also more likely $(49.1 \%$ vs $20.4 \%)$ to present to EDs (for any condition) with triage scores of 4 or 5 (for semiurgent or non-urgent cases) during the 1-year follow-up, suggesting EDs being used to fill the gaps in primary care or specialist services in rural areas.

A higher proportion of rural patients had a Charlson index of 1-2 although a small but significantly larger proportion of metropolitan patients (being older) scored $>3$ (table 1). Despite some statistical differences between metropolitan and rural patients, there was a high prevalence of potential antecedent HF risk factors including IHD, hypertension, atrial fibrillation, diabetes, chronic kidney disease, COPD, cerebrovascular disease and rheumatic and non-rheumatic valvular heart disease in both subpopulations (see table 1). Rates of coronary interventions (prior to or on index admissions) were low overall but significantly lower in rural patients. When adjusted for age, sex, period, Aboriginality and Charlson comorbidity index, rural patients with HF were less likely to have coronary angiography compared with metropolitan patients (risk-adjusted $\mathrm{OR}=0.81 \quad(95 \%$ CI 0.77 to $0.86, \mathrm{p}<0.001)$ ).

Crude 30-day and 1-year cumulative all-cause mortality and unadjusted risk were not significantly different between metropolitan and rural patients with first HF hospitalisation (tables 1 and 2). After age adjustment only, patients from rural areas had a higher risk of 30-day death (OR 1.16 (95\% CI 1.01 to 1.33$)$ ) and 1-year death in 30-day survivors (HR 1.11 (95\% CI 1.01 to 1.23), see table 2). The difference in survival between rural and metropolitan patients increased with further adjustment for sociodemographic differences including Aboriginality, SEIFA (as proxy for socioeconomic status), private insurance status, emergency presentation and the Charlson comorbidity index, with OR of 1.26 and HR of 1.14. The association between rurality and mortality persisted between the two subpopulations after further adjustment to include other individual comorbidities of interest, significant interaction effects and interventions (see table 2). The addition of the weighted Charlson index to the 30-day model (using a variation of the administrative claims model $)^{20}$ improved the 'c' statistic (under the receiver operating characteristic curve) from 0.656 to 0.714 .

No significant interactions were found between sex and rurality, and Aboriginality and rurality (as location of residence). Further evaluation of mortality in men and women separately and in younger $(<55$ years $)$ and older patients showed similar ORs/HRs of death at 30 days and 1 year (in 30-day survivors) in rural patients compared with metropolitan patients. 
Table 1 Baseline characteristics and crude mortality of metropolitan versus rural patients with a 'first-ever' (index) admission for heart failure between 2000 and 2009

\begin{tabular}{|c|c|c|c|}
\hline Description & Metropolitan, n (\%) & Rural, n (\%) & p Value \\
\hline \multicolumn{4}{|l|}{ Cases by ARIA classification ${ }^{1}$} \\
\hline Major city & 9006 (69.9) & & \\
\hline Inner regional & $3874(30.1)$ & $1182(26.3)$ & \\
\hline Outer regional & & 1807 (40.2) & \\
\hline Remote & & $477(10.6)$ & \\
\hline Very remote & & $1033(23.0)$ & \\
\hline Total cases & $12880(74.1)$ & $4499(25.9)$ & \\
\hline Women, n (\%) & $5511(42.8)$ & $1833(40.7)$ & 0.017 \\
\hline Mean age $\pm S D$ (years) & $70.8 \pm 11.7$ & $67.5 \pm 13.4$ & $<0.001$ \\
\hline \multicolumn{4}{|l|}{ Age groups (years), n (\%) } \\
\hline $20-34$ & $167(1.3)$ & $117(2.6)$ & $<0.001$ \\
\hline $35-49$ & $655(5.1)$ & $382(8.5)$ & \\
\hline $50-64$ & $2294(17.8)$ & $1039(23.1)$ & \\
\hline $65-84$ & $9764(75.8)$ & $2961(65.8)$ & \\
\hline Aboriginal patients, n (\%) & 241 (1.9) & $772(17.2)$ & $<0.001$ \\
\hline Length of stay, mean days $\pm S D$ & $7.1 \pm 8.6$ & $6.4 \pm 15.8$ & 0.001 \\
\hline \multicolumn{4}{|l|}{ Hospital type } \\
\hline Metro tertiary/teaching & $7212(56.0)$ & $543(12.1)$ & $<0.001$ for all \\
\hline Metro/non-teaching & $1282(10.0)$ & $28(0.6)$ & \\
\hline Rural regional & $48(0.4)$ & 1524 (33.9) & \\
\hline Rural district/small & $58(0.5)$ & $1835(40.8)$ & \\
\hline Private & 4280 (33.2) & $569(12.7)$ & \\
\hline Emergency admission, $\mathrm{n}(\%)$ & 12095 (93.9) & $4265(94.8)$ & 0.028 \\
\hline Private health insurance, $\mathrm{n}(\%)$ & $4197(32.6)$ & $915(20.3)$ & $<0.001$ \\
\hline \multicolumn{4}{|l|}{ SEIFA (socioeconomic status), $\mathrm{n}(\%)$} \\
\hline First quintile (most disadvantaged) & $3(0.2)$ & $1182(26.5)$ & $<0.001$ for all \\
\hline Second quintile & 1693 (13.2) & $1085(24.3)$ & \\
\hline Third quintile & 4827 (37.4) & $1476(33.1)$ & \\
\hline Fourth quintile & 2918 (22.6) & $631(14.1)$ & \\
\hline Fifth quintile (least disadvantaged) & $3439(26.6)$ & $89(2.0)$ & \\
\hline \multicolumn{4}{|l|}{ Source of referral-professional, n (\%) } \\
\hline General practitioner & $628(4.9)$ & $838(18.4)$ & $<0.001$ \\
\hline Specialist clinician & 3235 (25.2) & $688(15.1)$ & \\
\hline Outpatient department clinician & $534(4.1)$ & $137(3.0)$ & \\
\hline ED clinician & $7650(59.6)$ & $2527(55.6)$ & \\
\hline Hospital clinician & $89(0.7)$ & $67(1.5)$ & \\
\hline Community health clinician & $16(0.1)$ & $36(0.8)$ & \\
\hline Others & $106(0.8)$ & $33(0.7)$ & \\
\hline Missing & $572(4.5)$ & $221(4.9)$ & \\
\hline \multicolumn{4}{|l|}{ Mode of transport to hospital, n (\%) } \\
\hline Private/public transport & 6193 (48.3) & 2952 (64.9) & $<0.001$ \\
\hline Ambulance-patient transport only & $542(4.2)$ & $88(1.9)$ & \\
\hline Ambulance-emergency & $4938(38.5)$ & $884(19.4)$ & \\
\hline Royal Flying Doctor Service & $16(0.1)$ & $130(2.9)$ & \\
\hline Other & $115(0.9)$ & $156(3.4)$ & \\
\hline Missing & $1026(8.0)$ & $337(7.4)$ & \\
\hline \multicolumn{4}{|l|}{ Comorbidities, n (\%) ${ }^{\star}$} \\
\hline All ischaemic heart disease $†$ & $6426(49.9)$ & $1895(42.1)$ & 0.001 \\
\hline Acute myocardial infarction & $2242(17.4)$ & $636(14.1)$ & $<0.001$ \\
\hline
\end{tabular}




\begin{tabular}{|c|c|c|c|}
\hline Description & Metropolitan, n (\%) & Rural, n (\%) & p Value \\
\hline Unstable angina & $1987(15.4)$ & $485(10.8)$ & $<0.001$ \\
\hline Hypertension & 7194 (55.9) & $2408(53.5)$ & 0.007 \\
\hline Atrial fibrillation & 5579 (43.3) & 1692 (37.6) & $<0.001$ \\
\hline Diabetes & 4104 (31.9) & 1543 (34.3) & 0.003 \\
\hline Chronic kidney disease & $2851(22.1)$ & $918(20.4)$ & 0.015 \\
\hline Renal failure & $415(3.2)$ & $181(4.0)$ & 0.012 \\
\hline COPD & $2600(20.2)$ & $1146(25.5)$ & $<0.001$ \\
\hline Cerebrovascular disease & $1404(10.9)$ & $391(8.7)$ & $<0.001$ \\
\hline $\begin{array}{l}\text { Rheumatic heart disease/rheumatic } \\
\text { valvular heart disease }\end{array}$ & $1868(14.5)$ & $526(11.7)$ & $<0.001$ \\
\hline Valvular heart disease, non-rheumatic & $2663(20.7)$ & $703(15.6)$ & $<0.001$ \\
\hline \multicolumn{4}{|l|}{ Interventions, n (\%) } \\
\hline History of $\mathrm{PCl}$ & $779(6.1)$ & $203(4.5)$ & $<0.001$ \\
\hline History of CABG & $342(2.7)$ & $118(2.6)$ & 0.891 \\
\hline Index $\mathrm{PCl}$ & $228(1.8)$ & $36(0.8)$ & $<0.001$ \\
\hline Index CABG & $374(2.9)$ & $86(1.9)$ & $<0.001$ \\
\hline Coronary angiography & $6003(46.6)$ & $1711(38.0)$ & $<0.001$ \\
\hline \multicolumn{4}{|l|}{ Charlson Index n (\%) } \\
\hline 0 & $73(0.6)$ & $32(0.7)$ & \multirow{4}{*}{0.001 for all } \\
\hline $1-2$ & $5780(44.9)$ & $2158(48.0)$ & \\
\hline $3-4$ & $3474(27.0)$ & $1164(25.9)$ & \\
\hline$>4$ & $3553(27.6)$ & $1145(25.4)$ & \\
\hline \multicolumn{4}{|l|}{ Crude cumulative mortality } \\
\hline 30-day case death $\ddagger$ & $838(6.6)$ & $306(6.9)$ & 0.474 \\
\hline 1-year mortality§ & $2364(20.5)$ & $829(20.7)$ & 0.799 \\
\hline $\begin{array}{l}\text { Mean presentations to ED within } \\
1 \text {-year follow-up, } n \pm S D\end{array}$ & $2.8 \pm 3.1$ & $4.9 \pm 5.7$ & $<0.001$ \\
\hline \multicolumn{4}{|c|}{$\begin{array}{l}\text { Continuous variables expressed as mean } \pm \text { SD. Categorical variables expressed as proportions, } n(\%) \text {. } p \text { Value is for difference between metro } \\
\text { and rural patients. } \\
\text { *Patients could have multiple comorbidities. } \\
\text { †All ischaemic heart disease includes acute myocardial infarction. } \\
\text { †Patients admitted in December } 2009 \text { were excluded from analysis. } \\
\text { §Year } 2009 \text { was used as a follow-up period. } \\
\text { ARIA, Accessibility/Remoteness Index of Australia; CABG, coronary artery bypass grafting; COPD, chronic obstructive pulmonary disease; } \\
\text { ED, emergency department; PCI, percutaneous coronary intervention; SEIFA, Socioeconomic Indices for Areas. }\end{array}$} \\
\hline
\end{tabular}

A sensitivity analysis using three levels of geographical residence (metropolitan, regional and remote) indicates that regional patients had significantly higher adjusted 30-day and 1-year mortality (in 30-day survivors) than metropolitan patients (table 3). However, the slightly higher OR for 30-day mortality in remote patients (1.29; $95 \%$ CI 0.98 to 1.69 ) did not reach significance in the fully adjusted model, and the adjusted HR for 1-year mortality (in 30-day survivors) was not higher in remote patients (table 3 ).

\section{DISCUSSION}

HF is a complex, disabling and potentially deadly clinical syndrome, of increasing public health importance as the population ages. ${ }^{21}$ Our study examined hospitalised patients with 'first-ever' HF, and accordingly, a vast majority $(>93 \%)$ were emergency presentations to hospital. In this population-based cohort of patients, we found that a sizeable minority of patients $(26 \%)$ live in rural/remote Western Australia. The majority of the rural patients with $\mathrm{HF}$ were from areas of social disadvantage with limited or no access to specialist services for HF, as others have found. ${ }^{22} 23$ Rural area of residence was consistently associated with higher risk-adjusted OR and $\mathrm{HR}$ of short-term mortality at 30 days and 1 year (in 30-day survivors) respectively, compared with metropolitan patients, even after controlling for socioeconomic status, Aboriginality, private insurance status and risk factors. The same findings were observed in the subgroup analyses: men and women who lived in rural/remote areas of Western Australia, as well as in older patients aged 55 years and over.

Earlier research by Clark et $a l^{24}$ showed a significantly higher prevalence of congestive HF in rural compared with metropolitan areas among patients aged 60 years and over. Furthermore, rates of echocardiography for diagnosis or specialist referrals and rate of prescribing 
Table 2 Step-wise risk adjustment for 30-day and 1-year mortality (in 30-day survivors) in rural patients with index heart failure versus metropolitan patients

\begin{tabular}{|c|c|c|}
\hline Risk adjustment & OR $(95 \% \mathrm{Cl})$ & p Value \\
\hline \multicolumn{3}{|l|}{ Death at 30 days from index admission } \\
\hline Unadjusted & $1.05(0.92$ to 1.20$)$ & 0.487 \\
\hline \multicolumn{3}{|l|}{ Rural patients adjusted for } \\
\hline Age & $1.16(1.01$ to 1.33$)$ & 0.035 \\
\hline \multicolumn{3}{|l|}{ SEIFA, private insurance status } \\
\hline Model 2+emergency presentation, Charlson index & $1.26(1.07$ to 1.49$)$ & 0.005 \\
\hline $\begin{array}{l}\text { Model 3+individual comorbidities*, interactions, insurance status, } \\
\text { emergency presentation }\end{array}$ & $1.26(1.07$ to 1.48$)$ & 0.007 \\
\hline Model 4+PCl/CABG & $1.25(1.06$ to 1.48$)$ & 0.007 \\
\hline \multicolumn{3}{|l|}{ Death at 1 year in 30-day survivors } \\
\hline Unadjusted & $0.99(0.90$ to 1.09$)$ & 0.866 \\
\hline \multicolumn{3}{|l|}{ Rural patients adjusted for } \\
\hline Age & $1.11(1.01$ to 1.23$)$ & 0.030 \\
\hline Model 2: age, sex, period, Aboriginality, SEIFA, private insurance & $1.06(0.95$ to 1.20$)$ & 0.291 \\
\hline Model 2+emergency presentation, Charlson index & $1.14(1.02$ to 1.28$)$ & 0.027 \\
\hline Model 3+individual comorbidities ${ }^{\star}$, interactions & $1.14(1.02$ to 1.28$)$ & 0.032 \\
\hline Model 4+PCI/CABG & $1.13(1.02$ to 1.27$)$ & 0.040 \\
\hline \multicolumn{3}{|c|}{$\begin{array}{l}\text { *Individual comorbidities adjusted in the models include hypertension, atrial fibrillation, rheumatic heart disease, diabetes, chronic kidney } \\
\text { disease, renal failure, unstable angina, acute myocardial infarction, other ischaemic heart disease, cerebrovascular disease and chronic } \\
\text { obstructive pulmonary disease. } \\
\text { PCI/CABG, percutaneous coronary intervention/coronary artery bypass grafting; SEIFA, Socioeconomic Index for Areas. }\end{array}$} \\
\hline
\end{tabular}

ACE inhibitor drugs were consistently lower in rural compared with metropolitan areas. ${ }^{24}$ Different pharmacotherapy patterns in rural and metropolitan Canadian patients with $\mathrm{HF}$ have also been reported. ${ }^{9}$ We found that receipt of coronary angiography or interventions were lower in rural patients, consistent with the previous findings, ${ }^{10} 24$ although disparity in discharge medications was not examined in our study.
Western Australia is geographically large, being the size of Western Europe, with much of its area sparsely populated. Accordingly, the tyranny of distance and lack of transport (as the interface between different entry points to the healthcare system) are major obstacles to accessing appropriate healthcare for rural West Australians. Access to appropriate specialist expertise also requires transfer between services and there are

Table 3 Sensitivity analysis showing step-wise risk adjustment for 30-day and 1-year mortality (in 30-day survivors) in patients with index heart failure by level of residential location

\begin{tabular}{|c|c|c|c|c|}
\hline \multirow[b]{2}{*}{ Risk adjustment } & \multicolumn{2}{|l|}{ Regional WA } & \multicolumn{2}{|c|}{ Remote/very remote WA } \\
\hline & OR (95\% Cl) & p Value & OR (95\% Cl) & p Value \\
\hline \multicolumn{5}{|l|}{ Death at 30 days from index admission* } \\
\hline Unadjusted & $1.10(0.94$ to 1.29$)$ & 0.227 & $0.95(0.76$ to 1.19$)$ & 0.649 \\
\hline \multicolumn{5}{|l|}{ Adjusted for } \\
\hline Age & $1.08(0.99$ to 1.17$)$ & 0.068 & $1.20(1.07$ to 1.36$)$ & 0.002 \\
\hline Age, sex, period, Aboriginality, SEIFA, private insurance & $1.17(0.98$ to 1.38$)$ & 0.083 & $1.21(0.93$ to 1.59$)$ & 0.153 \\
\hline Model 2+emergency presentation, Charlson index & $1.24(1.04$ to 1.48$)$ & 0.015 & $1.34(1.02$ to 1.75$)$ & 0.033 \\
\hline Model 3+individual comorbidities, interactions & 1.25 (1.04 to 1.49$)$ & 0.014 & $1.28(0.98$ to 1.68$)$ & 0.069 \\
\hline Model 4+PCI/CABG & $1.24(1.04$ to 1.48$)$ & 0.016 & $1.29(0.98$ to 1.69$)$ & 0.071 \\
\hline \multicolumn{5}{|l|}{ Death at 1 year in 30 -day survivors ${ }^{*}$} \\
\hline Unadjusted & $1.09(0.97$ to 1.21$)$ & 0.136 & $0.81(0.68$ to 0.95$)$ & 0.011 \\
\hline \multicolumn{5}{|l|}{ Adjusted for } \\
\hline Age & $1.13(1.01$ to 1.26$)$ & 0.030 & $1.07(0.91$ to 1.27$)$ & 0.419 \\
\hline Age, sex, period, Aboriginality, SEIFA, private insurance & $1.10(0.97$ to 1.24$)$ & 0.139 & $0.93(0.76$ to 1.14$)$ & 0.477 \\
\hline Model 2+emergency presentation, Charlson index & $1.17(1.03$ to 1.32$)$ & 0.013 & $1.04(0.86$ to 1.27$)$ & 0.670 \\
\hline Model 3+individual comorbidities, interactions & $1.18(1.04$ to 1.33$)$ & 0.010 & $1.02(0.84$ to 1.24$)$ & 0.878 \\
\hline Model 4+PCI/CABG & $1.17(1.03$ to 1.32$)$ & 0.014 & $1.02(0.84$ to 1.24$)$ & 0.870 \\
\hline
\end{tabular}

${ }^{*}$ Patients with metropolitan residence as the reference group.

$\mathrm{PCI} / \mathrm{CABG}$, percutaneous coronary intervention/coronary artery bypass grafting; SEIFA, Socioeconomic Index for Areas; WA, Western Australia. 
many reasons why such transfers may not occur. Moreover, there may be limited access to comprehensive primary healthcare services, poor integration between different levels of care and inadequate services to support ongoing home-based intervention and HF selfmanagement, ${ }^{25}$ HF-specific cardiac rehabilitation programmes $^{26}$ and socioculturally appropriate services. ${ }^{27-29}$ Hence, the dimension of metro-rural divide in the context of Western Australia is larger than that which occurs in other states. ${ }^{30}$ Issues of rural and remote health are much more complex than merely the practice of health in another location $^{3}$ and are affected by issues such as workforce shortages and retention of healthcare workers, higher out-of-pocket costs and the time and cost of travel. ${ }^{3}$

Rural and remote patients with HF differed considerably from metropolitan patients including being younger, more socially disadvantaged and more likely to be Aboriginal. Despite Australia having universal health insurance through Medicare which allows free access to public hospital treatment and outpatient medical consultations and medications being subsidised, there remain barriers to specialist consultations for socially disadvantaged groups, particularly where upfront cash payments are required. An even more important disparity is the paucity of specialist cardiology care in regional/remote areas. This is evident from the differences in profiles of care between the two subpopulations and the findings that showed rural patients were utilising EDs to fill the gaps in the primary healthcare and the specialist services in rural areas. Other evidence shows that increasing private health insurance coverage in Australia has been associated with loss of equity after controlling for other factors. $^{30} 31$

The heterogeneity in the different geographical areas needs to be highlighted. However, our results showed that despite further adjustments for demographics, SEIFA and private health insurance status (both as a proxy for socioeconomic status), Aboriginality, emergency presentations, individual comorbidities and interventions, differential difference in mortality outcomes persisted for rural patients compared with metropolitan patients. It is plausible that the type of care received from regional, small district hospitals and/or rural primary care providers compared with metropolitan hospitals and urban general practices has a differential impact on mortality. Around $75 \%$ of the rural patients were managed at regional, small district hospitals, while a vast majority of urban patients were treated in tertiary and private hospitals. There might be another reason why fewer people have private insurance in rural areasbecause there are only two private hospitals in rural areas, and going in as a private patient in a public rural hospital offers little advantage. Hence, rural residents may not see a need for private insurance, and they probably think the likelihood of being admitted to a metro private hospital is low.

In the sensitivity analysis with the three levels for residential location, regional patients showed increased risk-adjusted ORs/HRs of 30-day and 1-year mortality (in 30-day survivors). The association for remote/very remote patients was marginally significant (for 30-day mortality) possibly because of a lack of power. However, previous work by Katzenellenbogen et $a l^{32}$ found that some older groups living in remote areas had lower MI rates than metropolitan residents, suggesting a possible migration effect of remote patients with heart disease moving to regional/metro centres. The data from the current study may reflect such a phenomenon, with remote patients with $\mathrm{HF}$ moving to more accessible centres after their incident event and thus benefiting through improved 1-year survival.

Our results are consistent with other studies from Canada and the USA which also reported worse outcomes in rural versus metropolitan patients with $\mathrm{HF}^{8-10}$ The same rural-metropolitan differential in Western Australia was reported for the incidence of MI in Western Australia. ${ }^{32}$ However, conflicting evidence was reported from a CVD risk study on South-West Victoria and North-West Adelaide, Australia. ${ }^{30}$ That study examined cardiovascular mortality rates without comprehensive adjustment and only a small proportion of the patients examined were Aboriginal. ${ }^{30}$ There is also a contextual difference in that HF has high mortality with patients often presenting with heavy comorbidity burden.

The problem of inequalities in health burden and access to healthcare related to rurality and remoteness is a common theme across many countries including high socioeconomic countries such as Australia and Canada. It is therefore an important issue that is relevant to health policy, health service delivery and healthcare planning in many countries beyond the local context.

The strengths of this study lie in the quality and near complete ascertainment of the short-term and long-term mortality after first HF hospitalisation using linked administrative data in Western Australia, ${ }^{11}$ and the previous validation with respect to a principal diagnosis of HF. ${ }^{14}$ However, sociodeprivation was derived using an area-based measure which gives rise to potential misclassification at an individual level. We have no information as to why people choose not to have private health insurance. Our study also lacked information on use of medications in our cohort. However, in a separate study undertaken by our team, ${ }^{33}$ the authors found adjusted evidence-based prescription at discharge for patients with acute coronary syndrome was significantly lower in district hospitals versus metropolitan teaching hospitals (OR 0.51 (95\% CI 0.32 to 0.82$)$ ), as well also in patients with regional versus metropolitan residence (OR 0.55 (95\% CI 0.39 to 0.77$)$ ). This finding is also likely applicable to the uptake and adherence to evidence-based therapy for patients with HF discharged from nontertiary and rural care hospitals. We have previously shown that the discharge prescription of evidence-based HF medications had a significant impact on subsequent survival. $^{34}$ 


\section{CONCLUSIONS}

This study highlights the impact of geographical or spatial isolation on mortality outcomes in patients with $\mathrm{HF}$ as the first step in understanding rural-urban differences. From the health policy perspective, the higher rural mortality likely points to the inequalities in the availability and access to appropriate medical care, rather than compositional differences in rural and metropolitan patients with HF. Rural Western Australia is not homogeneous and the proportion of Aboriginal people increases with remoteness. This has implications for the provision of collaborative models of care for chronic disease management and secondary prevention of $\mathrm{HF}$ in rural areas.

\section{Author affiliations}

${ }^{1}$ Western Australian Centre for Rural Health, University of Western Australia, Perth, Western Australia, Australia

${ }^{2}$ Sir Charles Gairdner Hospital Unit, School of Medicine and Pharmacology, University of Western Australia, Perth, Western Australia, Australia

${ }^{3}$ School of Population Health, University of Western Australia, Perth, Western Australia, Australia

Acknowledgements The authors thank the Western Australian Data Linkage Branch and the staff of the Inpatient Data Collections for the provision of the data and the Registry of Births, Deaths and Marriages for providing the death data.

Contributors All authors critically reviewed and contributed to the intellectual content of the manuscript. T-HKT, JMK, MK, SCT and JH were involved with the conception of the study. T-HKT performed the statistical analyses, supported by MK and drafted the manuscript. SCT, JH and MH provided the clinical expertise. All authors have read and approved the final version of the manuscript.

Funding The study had been supported by the National Health and Medical Research Council (NHMRC) project grant (\#1031057). The Western Australian Centre for Rural Health receives funding from the Department of Health and Ageing. JMK is funded by an NHMRC Early Career Fellowship (\#037429).

Competing interests None.

Ethics approval The Western Australia Aboriginal Health Ethics Committee and Human Research Ethics Committees of the Department of Health Western Australia and The University of Western Australia.

Provenance and peer review Not commissioned; externally peer reviewed.

Data sharing statement No additional data are available. Data provided by the Western Australian Department of Health, via the Data Linkage Branch. Linked personal health information is confidential and cannot be shared. The investigators and institution are bound by confidentiality agreements which prevent complying with this Data Sharing Policy.

Open Access This is an Open Access article distributed in accordance with the Creative Commons Attribution Non Commercial (CC BY-NC 3.0) license, which permits others to distribute, remix, adapt, build upon this work noncommercially, and license their derivative works on different terms, provided the original work is properly cited and the use is non-commercial. See: http:// creativecommons.org/licenses/by-nc/3.0/

\section{REFERENCES}

1. Australian Institute of Health and Welfare. Rural, regional and remote health-indicators of health. Canberra: AlHW, 2005. Cat. No. PHE 59.

2. AlHW 2010. Cardiovascular medicines and primary health care: a regional analysis. Canberra: AlHW, 2010.
3. Wakerman J, Humphreys JS. Rural health: why it matters. Med J Aust 2002;176:457-8.

4. Dixon J, Welch N. Researching the rural-metropolitan health differential using the 'social determinants of health'. Aust J Rural Health 2000;8:254-60.

5. Australian Bureau of Statistics. Population distribution, Aboriginal and Torres Strait Islander Australians. ABS, 2006. 2007 Cat. no. 3238.0.55.001.

6. Humphreys J, Hegney D, Lipscombe J, et al. Whither rural health? Reviewing a decade of progress in rural health. Aust $J$ Rural Health 2002;10:2-14.

7. Levy D, Kenchaiah S, Larson MG, et al. Long-term trends in the incidence of and survival with heart failure. $N$ Engl J Med 2002;347:1397-402.

8. Muus KJ, Knudson A, Klug MG, et al. Effect of post-discharge follow-up care on re-admissions among US veterans with congestive heart failure: a rural-urban comparison. Rural Remote Health 2010;10:1447

9. Gamble JM, Eurich DT, Ezekowitz JA, et al. Patterns of care and outcomes differ for urban versus rural patients with newly diagnosed heart failure, even in a universal healthcare system. Circ Heart Fail 2011;4:317-23.

10. Jin $\mathrm{Y}$, Quan H, Cujec B, et al. Rural and urban outcomes after hospitalization for congestive heart failure in Alberta, Canada. J Card Fail 2003;9:278-85.

11. Holman CD, Bass AJ, Rosman DL, et al. A decade of data linkage in Western Australia: strategic design, applications and benefits of the WA data linkage system. Aust Health Rev 2008;32: 766-77.

12. Teng TH, Finn J, Hobbs $M$, et al. Heart failure: incidence, case fatality, and hospitalization rates in Western Australia between 1990 and 2005. Circ Heart Fail 2010;3:236-43.

13. Teng TH, Katzenellenbogen JM, Thompson SC, et al. Incidence of first heart failure hospitalization and outcomes in Aboriginal and non-Aboriginal patients in Western Australia, 2000-2009. Int J Cardiol 2014;173:110-17.

14. Teng TH, Finn J, Hung J, et al. A validation study: how effective is the hospital morbidity data as a surveillance tool for heart failure in Western Australia? Aust N Z J Public Health 2008;32:405-7.

15. Australian Institute of Health and Welfare. Rural, regional and remote health: a guide to remoteness classification. Canberra: ACT, 2004. Cat no. PHE 53.

16. Geographic Information Systems EB, Public Health Division. Department of Health. Health geographical classification, version 4.0. I. Perth, WA: Department of Health, 2013.

17. Australian Bureau of Statistics. Information paper: census of population and housing-socio-economic indexes for areas, Australia. Canberra: ABS, 2003. Cat no. 2033.055.001.

18. Charlson ME, Pompei $\mathrm{P}$, Ales $\mathrm{KL}$, et al. A new method of classifying prognostic comorbidity in longitudinal studies: development and validation. J Chronic Dis 1987;40:373-83.

19. Romano PS, Roos LL, Jollis JG. Adapting a clinical comorbidity index for use with ICD-9-CM administrative data: differing perspectives. J Clin Epidemiol 1993;46:1075-9.

20. Krumholz HM, Wang Y, Mattera JA, et al. An administrative claims model suitable for profiling hospital performance based on 30-day mortality rates among patients with heart failure. Circulation 2006;113:1693-701.

21. Krum H, Jelinek MV, Stewart S, et al. Guidelines for the prevention, detection and management of people with chronic heart failure in Australia 2006. Med J Aust 2006;185:549-57.

22. Wakerman J, Humphreys JS, Wells RW, et al. Improving rural and remote health. Med J Aust 2007:186:486.

23. Unger CC, Warren N, Canway R, et al. Type 2 diabetes, cardiovascular disease and the utilisation of primary care in urban and regional settings. Rural Remote Health 2011;11:1795.

24. Clark RA, Eckert KA, Stewart S, et al. Rural and urban differentials in primary care management of chronic heart failure: new data from the CASE study. Med J Aust 2007;186:441-5.

25. Stewart S, Pearson S, Horowitz JD. Effects of a home-based intervention among patients with congestive heart failure discharged from acute hospital care. Arch Intern Med 1998;158: 1067-72.

26. Davidson PM, Cockburn J, Newton PJ, et al. Can a heart failure-specific cardiac rehabilitation program decrease hospitalizations and improve outcomes in high-risk patients? Eur J Cardiovasc Prev Rehabil 2010;17:393-402.

27. Digiacomo M, Davidson PM, Taylor KP, et al. Health information system linkage and coordination are critical for increasing access to secondary prevention in Aboriginal health: a qualitative study. Qual Prim Care 2010;18:17-26. 
28. DiGiacomo ML, Thompson SC, Smith JS, et al. 'I don't know why they don't come': barriers to participation in cardiac rehabilitation. Aust Health Rev 2010;34:452-7.

29. Thompson SC, Digiacomo ML, Smith JS, et al. Are the processes recommended by the NHMRC for improving cardiac rehabilitation (CR) for Aboriginal and Torres Strait Islander people being implemented?: an assessment of CR services across Western Australia. Aust N Z Health Policy 2009; 6:29.

30. Tideman P, Taylor AW, Janus E, et al. A comparison of Australian rural and metropolitan cardiovascular risk and mortality: the Greater Green Triangle and North West Adelaide population surveys. BMJ Open 2013;3:e003203.
31. Hindle D, McAuley I. The effects of increased private health insurance: a review of the evidence. Aust Health Rev 2004;28:119-38.

32. Katzenellenbogen JM, Sanfilippo FM, Hobbs MS, et al. Complex impact of remoteness on the incidence of myocardial infarction in Aboriginal and non-Aboriginal people in Western Australia. Aust $J$ Rural Health 2012;20:305-11.

33. Gausia K, Katzenellenbogen JM, Sanfilippo FM, et al. Evidencebased prescribing of drugs for secondary prevention of acute coronary syndrome in Aboriginal and non-Aboriginal patients admitted to Western Australian hospitals. Intern Med J 2014;44:353-61.

34. Teng TH, Hung J, Finn J. The effect of evidence-based medication use on long-term survival in patients hospitalized for heart failure in Western Australia. Med J Aust 2010;192:306-10. 